Ciência Florestal, Santa Maria, v. 26, n. 3, p. 811-823, jul.-set., 2016

ISSN 0103-9954

\title{
ATRIBUTOS EDÁFICOS E RESISTÊNCIA A PENETRAÇÃO EM ÁREAS DE SISTEMAS AGROFLORESTAIS NO SUDOESTE AMAZÔNICO
}

\author{
SOIL ATTRIBUTES AND RESISTANCE TO PENETRATION IN AGROFORESTRY SYSTEM AREAS \\ IN SOUTHWESTERN AMAZON
}

\author{
Wanderson Henrique do Couto ${ }^{1}$ Lucia Helena Cunha dos Anjos ${ }^{2}$ Paulo Guilherme Salvador Wadt ${ }^{3}$ \\ Marcos Gervasio Pereira ${ }^{4}$
}

\section{RESUMO}

Os sistemas agroflorestais (SAFs) têm sido propostos para aliar a preservação das florestas a modelos agrícolas sustentáveis. O objetivo do estudo foi avaliar atributos edáficos e correlacioná-los com a resistência mecânica do solo à penetração (RMSP) de três classes de solo na Amazônia Ocidental, em áreas de SAFs do projeto Reflorestamento Econômico Consorciado e Adensado (RECA), em Rondônia. Foram selecionadas 14 áreas de SAF com 20 anos de implantação e composição, estrutura e espaçamento entre árvores semelhantes, além de duas áreas de referência, com cobertura de mata e pastagem. Além das avaliações de atributos dos solos, foram realizados testes para medir a RMSP e determinado o estoque de C no solo até um metro. Os perfis de solo foram classificados como Latossolos, Argissolos e Cambissolos, todos com argila de baixa atividade e reduzidos estoques de nutrientes, caráter distrófico e às vezes alumínico. Nas áreas de SAF, os valores de RMSP variaram de 0,96 a 4,59 MPa, sem restrições ao sistema radicular em superfície, porém, aumentando em profundidade. Em geral, os Latossolos mostraram menores valores de RMSP que os Cambissolos e Argissolos, e os valores mais altos ocorreram na área de referência com pastagem. Os estoques de $\mathrm{C}$ variaram de 45,19 a 126,04 $\mathrm{Mg} \mathrm{C} \mathrm{ha}^{-1}$, e metade das áreas de SAF apresentaram valores próximos ou até superiores aos da área de mata. A análise de componentes principais mostrou uma distinção entre os Cambissolos e as demais classes de solos. Os principais atributos que diferenciaram as áreas foram o teor de $\mathrm{Al}$, pH e a granulometria.

Palavras-chave: formação Solimões; estoque de carbono; resistência do solo à penetração.

\section{ABSTRACT}

Agroforestry systems (AFS) have been proposed to combine the forest preservation with sustainable agricultural models. The objective of this study was to evaluate soil attributes and to correlate them with soil mechanical resistance to penetration (SMRP) of three soil classes in southwestern Amazon, in AFS areas of the project RECA, in Rondônia state. Were selected 14 areas of AFS with 20 years and similar composition, structure and tree spacing, plus two reference areas, with pasture and forest. Besides soil attributes, SMRP and soil $\mathrm{C}$ stock up to one meter depth were measured. Soils were classified as Oxisols, Ultisols, and Inceptisols, all with low activity clays and low nutrient levels, dystrophic character and some with very high aluminum. In the AFS areas, the SMRP values varied from 0.96 to $4.59 \mathrm{MPa}$, without restriction to plant root system in the surface, but increasing with soil depth. In general, the Oxisols showed lower values of SMRP than the Inceptisols and Ultisols, and the highest values were in the pasture reference area. The

1 Engenheiro Agrônomo, Secretaria de Agricultura Familiar e Desenvolvimento Agrário, SBN - Quadra 1, Ed. Palácio do Desenvolvimento - Sala 801, CEP 70057-900, Brasília (DF), Brasil. wanderson.couto@mda.gov.br

2 Engenheira Agrônoma, Professora do Departamento de Solos, Universidade Federal Rural do Rio de Janeiro, BR 465, km 7, CEP 23890-000, Seropédica (RJ), Brasil. lanjosrural@gmail.com

3 Engenheiro Agrônomo, Pesquisador A da Empresa Brasileira de Pesquisa Agropecuária, Rod. BR 364, km 5,5, CEP 76900-970, Porto Velho (RO), Brasil.paulo.wadt@embrapa.br

4 Engenheiro Agrônomo, Professor do Departamento de Solos, Universidade Federal Rural do Rio de Janeiro, BR 465, km 7, CEP 23890-000, Seropédica (RJ), Brasil. gervasio@ufrrj.br

Recebido para publicação em 3/08/2012 e aceito em 28/11/2014

Ci. Fl., v. 26, n. 3, jul.-set., 2016 
carbon stock varied from 45.19 to $126.04 \mathrm{Mg} \mathrm{C} \mathrm{ha}^{-1}$, and half of the AFS areas showed values near or even higher than the $\mathrm{C}$ stocks in the forest reference area. The principal component analyses showed a distinction between Inceptisols and the other soil classes. The main attributes differentiating the areas were Al content, $\mathrm{pH}$ and granulometry.

Keywords: Solimões formation; carbon stock; soil resistance to penetration.

\section{INTRODUÇÃO}

O bioma Amazônia vem sendo afetado pela expansão das fronteiras agrícolas, com intensificação da retirada de produtos madeireiros e, em seguida, a pressão por abertura de novas áreas para agricultura e pecuária. Nesse cenário, os sistemas agroflorestais (SAFs) vêm se tornando a alternativa de menor impacto na produção de alimentos e de madeira, e para o desenvolvimento econômico da região. Os SAFs permitem a consorciação de espécies nativas e introduzidas, a manutenção ou menor impacto sobre as propriedades edáficas, aliando a cultura local ao desenvolvimento agrícola. Ainda, pela característica de reconhecimento da experiência das comunidades, favorece a fixação das populações tradicionais. Porém, segundo Franke et al. (1998), o processo de seleção e implantação de SAFs na Amazônia tem sido feito de forma desordenada e sem a devida planificação, com o desconhecimento do potencial dos recursos naturais, tanto sobre as características do solo como as plantas que estão sendo cultivadas.

O sucesso dos SAFs está relacionado à escolha das espécies que o compõem, $o$ arranjo entre as plantas e em especial na escolha do local a ser implantado. Uma vez que, por se tratar de espécies perenes, as propriedades físicas do solo podem potencializar efeitos climáticos, comprometendo a produção e longevidade da cultura. A drenagem imperfeita dos solos restringe o desenvolvimento das raízes a sua porção superior mais aerada e, em épocas com deficit hídrico, essas plantas podem ter seu desenvolvimento comprometido. Nascimento et al. (2007) citam que o desenvolvimento radicular e a longevidade da cultura dependem de aspectos como: boa aeração, drenagem do solo e retenção de umidade; permitindo maior exploração do sistema radicular das plantas por volume de solo, possibilitando maior absorção de nutrientes.

Borges et al. (1999) afirmam que há uma relação direta entre a densidade do solo e a resistência mecânica do solo. Outros autores citam que a avaliação da Resistência Mecânica do Solo à Penetração (RMSP) permite a melhor estimativa de impedimentos à penetração de raízes, já que a RMSP resulta da interação de vários atributos do solo (BEUTLER \& CENTURION, 2004). Ainda, a RMSP é um indicador sensível da compactação do solo e, consequentemente, da facilidade de penetração das raízes no solo (RIBON et al., 2003).

As propriedades físicas podem ser alteradas pelo manejo do solo, sendo o tráfego de maquinário e/ou de animais, as práticas que mais causam impacto nessas propriedades (COLLARES et al., 2008). Porém, alguns solos naturalmente possuem condição física desfavorável ao desenvolvimento do sistema radicular, conforme descrevem Amaral et al. (1998), em Senador Guiomard (Acre). Os autores encontraram solos com elevados teores de argila e destacam que cerca de $60 \%$ dos perfis têm restrições à drenagem nos primeiros $40 \mathrm{~cm}$ de profundidade, além de apresentarem frequentemente horizontes plínticos.

O objetivo desse trabalho foi avaliar atributos morfológicos, químicos, físicos e resistência mecânica do solo à penetração em três ordens de solo na Amazônia Ocidental, em propriedades rurais em áreas de produção de SAFs do projeto Reflorestamento Econômico Consorciado e Adensado (RECA).

\section{MATERIAL E MÉTODOS}

A área (RECA) está localizada no distrito de Nova Califórnia, extremo oeste de Porto Velho, no $\mathrm{km} 160$ da rodovia BR 364, que liga as capitais Porto Velho - RO e Rio Branco - AC. A microrregião é conhecida como Ponta do Abunã. O clima é do tipo Am pela classificação de Köppen, que corresponde a tropical monçônico, com média da temperatura do ar durante o mês mais frio superior a $18^{\circ} \mathrm{C}$ (megatérmico) e período seco bem definido, no inverno, quando ocorre moderado deficit hídrico, com índices pluviométricos inferiores a $50 \mathrm{~mm}$ por mês. A média anual da precipitação varia entre 2.200 e $2.300 \mathrm{~mm}$ por ano.

Quantoàgeologia, aregiãodeNovaCalifórnia 
está inserida na Formação Solimões. Segundo Brasil (1976), é composta por: argilitos maciços ou com concreções carbonáticas e gipsíferas, vênulas de calcita e gipsita e ocasionalmente material vegetal carbonizados (turfa a linhito) com concreções de pirita, com fósseis de vertebrados e invertebrados, e estratificação cruzada de grande amplitude; argilitos variegados com estrutura laminada; siltitos maciços ou acamados; arenitos finos a grosseiros, em lente ou interdigitados com siltitos e argilitos, maciços ou estratificados, friáveis a bem compactados, de cimento calcífero com leitos tabulares de material carbonático e estratificações cruzadas de pequena a média amplitude; calcários síltico-argilosos e arenosos; arcóseo; arenitos limoníticos em leitos tabuliformes; e conglomerados polimíticos. O relevo da região se caracteriza por grandes áreas planas ou suave onduladas e com pequenos vales em "V". Segundo Acre (2006), a área estudada está localizada na Depressão do Endimari-Abunã e a unidade apresenta altitude variando entre 130 e 200 m. A superfície é suavemente dissecada, com topos tabulares e algumas áreas planas, e, no trecho que acompanha longitudinalmente o rio Abunã o relevo é pouco mais dissecado e com topos convexos.

Os SAFs nas propriedades que integram o RECA são baseados em três espécies amazônicas. O cupuaçu (Theobroma grandiflorum Schum.), a castanha-do-brasil (Bertholletia excelsa HBK) e a pupunha (Bactris gasipaes Kunth.). Os plantios no RECA têm arranjos adensados, com variações de idade e espaçamentos dessas culturas, além da introdução eventual de outras espécies. Quatorze propriedades com SAFs foram selecionadas para o estudo, todas de mesma composição de espécies, espaçamento (7 m x $4 \mathrm{~m}$ ) e idade de implantação (cerca de 20 anos). Foram selecionadas também duas áreas de referência, uma área de mata nativa primária e outra área utilizada como pastagem, principalmente de Brachiaria decumbens, por cerca de 20 anos, identificadas a seguir como "MATA" e "PASTAGEM", respectivamente, totalizando dezesseis áreas amostrais.

Em cada área foi aberta uma trincheira de pelo menos $1,5 \mathrm{~m}$ de profundidade, para descrição morfológica dos perfis e amostragem do solo, segundo Santos et al. (2005). Além destas, três minitrincheiras foram abertas para complementar a amostragem de solo para caracterização de fertilidade, em um total de quatro amostras em cada área de estudo. Para determinar o teor de umidade e a densidade do solo (Ds) foram coletadas amostras usando-se anel de Kopechy de $50 \mathrm{~cm}^{3}$ nas profundidades de $0-10,10-20,20-30$ e $30-40 \mathrm{~cm}$.

As coletas foram realizadas no final de maio de 2009, ao final do período chuvoso, quando foram realizados quatro testes para avaliação da RMSP no campo, com o penetrômetro de impacto modelo IAA/Planalsucar - Stolf. Para o cálculo de RMSP utilizou-se a equação de Stolf (1991) representado por $\operatorname{RMSP}=(5,8+6,89 \times \mathrm{N}) / 10,2$, em que: $\mathrm{RMSP}$ $=$ Resistência mecânica do solo à penetração, em $\mathrm{MPa}$ e $\mathrm{N}=$ Número de impactos por decímetro de profundidade.

A densidade do solo (Ds) e a densidade das partículas (Dp), ambas expressas em $\mathrm{Mg} \mathrm{m}^{-3}, \mathrm{o}$ volume total de poros (VTP, \%) e a granulometria (frações areia, silte e argila total e natural) foram obtidos, segundo Embrapa (1997). Foram determinados ainda o $\mathrm{pH}$, teores de bases $(\mathrm{Ca}, \mathrm{Mg}$ e $\mathrm{K})$, de acidez ( $\mathrm{H}+\mathrm{Al}$ e $\mathrm{Al})$ e $\mathrm{C}$ orgânico do solo (C org.), segundo métodos de Embrapa (1997). Os perfis de solo foram classificados segundo o Sistema Brasileiro de Classificação de Solos SiBCS (EMBRAPA, 2006).

Para determinação do estoque de $\mathrm{C}$, nas camadas do solo até um metro de profundidade, foram usados valores de Ds e C org. do solo. O estoque de $\mathrm{C}$ foi calculado em cada camada pela equação Est $\mathrm{C}=(\mathrm{C} \times$ Ds $\times \mathrm{E}) / 10$, em que: Est $\mathrm{C}$ representa o estoque de carbono $\left(\mathrm{Mg} \mathrm{ha}^{-1}\right)$; $\mathrm{C}$ indica o teor de C orgânico na camada avaliada $\left(\mathrm{g} \mathrm{kg}^{-1}\right)$; Ds é a densidade do solo $\left(\mathrm{Mg} \mathrm{m}^{-3}\right)$ e $\mathrm{E}$ a espessura $(\mathrm{cm})$ da camada em análise. Já o estoque total foi obtido pelo somatório dos resultados das camadas até um metro.

Para efeito de comparação entre a resistência mecânica do solo à penetração nas áreas estudadas, foi feita a subtração dos valores encontrados nas áreas de referência (MATA e PASTAGEM) e nas áreas estudadas.

A Análise de Componentes Principais (ACP) e a matriz de correlação de Pearson foram feitas utilizando o programa XLStat 7.5 com 0,05 de significância.

\section{RESULTADOS E DISCUSSÃO}

\section{Classificação e caracterização morfológica dos solos}

Foram identificadas no RECA as seguintes classes de solos: Cambissolos, Latossolos e 
Argissolos, com sete, cinco e quatro perfis, respectivamente (Tabela 1). A atividade de argila dos horizontes diagnósticos variou de 10 a $24 \mathrm{cmol}_{\mathrm{c}} \mathrm{kg}^{-1}$ nos Cambissolos, de 7 a $15 \mathrm{cmol}_{\mathrm{c}} \mathrm{kg}^{-1}$ nos Latossolos e de 15 a $20 \mathrm{cmol}_{\mathrm{c}} \mathrm{kg}^{-1}$ nos Argissolos. Os solos têm argila de baixa atividade e caráter distrófico ou alumínico, ou ainda alítico; diferindo de outros solos com materiais da Formação Solimões, e dos perfis descritos por Lima et al. (2006), que estudou uma topossequência no município de Benjamim Constant - AM, e relata como comum a mineralogia de argila de alta atividade nos solos originados de sedimentos da mesma formação.

Nas áreas do RECA, o relevo não é preponderante para distinção dos pedoambientes. $\mathrm{O}$ relevo regional tem poucas variações, sendo frequente o relevo plano a suave ondulado recortado por tramas de linhas de drenagem (rios e igarapés), nas quais o relevo pode chegar a ser ondulado. $\mathrm{O}$ fator de formação mais atuante na gênese dos solos é o material de origem, com as variações de deposição e estratificação dos sedimentos.

Os Latossolos são solos mais desenvolvidos, profundos e com variação de cores desde $10 \mathrm{R}$ a 7,5YR. A estrutura variou de granular a blocos subangulares e com grau de desenvolvimento de fraco a moderado. A consistência seca variou de macia a muito dura; a consistência úmida apresentouse friável e, em alguns horizontes, muito friável. A consistência molhada, em geral, foi plástica e pegajosa (Tabelas 2 a 4). Foi observado mosqueado em apenas um horizonte superficial, na área sob pastagem, possivelmente devido à compactação superficial pela atividade de pastejo intensiva e sem manejo apropriado. Os Cambissolos foram caracterizados por perfis rasos com forte influência do material originário, com horizonte transicional $\mathrm{BC}$ ou $\mathrm{C}$ dentro de $1,0 \mathrm{~m}$ da superfície, de aspecto adensado e estrutura similar à dos sedimentos. Em geral, apresentam restrição interna à drenagem, em profundidade e intensidade variável, marcadas pelas cores com mosqueado. Os Argissolos assemelhamse aos Cambissolos quanto à influência do material de origem, diferenciando-se pela eluviação e iluviação de argila, evidenciada pelo horizonte $\mathrm{E}$ ou pela cerosidade, respectivamente.

\section{Resistência mecânica do solo à penetração (RMSP) e relação com atributos físicos}

Não existe um valor ou faixa de valores consensual para RMSP limitante às culturas. Taylor et al. (1966), trabalharam em quatro tipos de solos e com plantas de soja em câmara de crescimento, com amostras de estrutura indeformada, e consideraram como valor limitante o de 2,0 MPa e acima de 3,5 $\mathrm{MPa}$ o crescimento de raízes é severamente limitado. Já o Soil Survey Staff (1993) classifica valores de RMSP abaixo de $2 \mathrm{MPa}$ como intermediários e baixos, e entre 2 e $4 \mathrm{MPa}$ seriam considerados altos. Porém, esses resultados, em geral, são para plantas de arquitetura radicular superficial e ciclo anual, que podem não ser apropriados para extrapolação em cultivos perenes ou espécies florestais. No estudo foram usados os valores de RMSP nas áreas de referência (MATA e PASTAGEM), além dos limites citados. Assim, as observações foram divididas em três classes: a primeira sem restrição para a penetração das raízes, com valores de RMSP menores que $2 \mathrm{MPa}$; a segunda restritiva à penetração de raízes, para RMSP entre 2 e 3,5 MPa; e a classe impeditiva, com RMSP acima de 3,5 MPa.

TABELA 1: Perfis de solo e sua classificação conforme o SiBCS (2006).

TABLE 1: Soil profiles and classification according to SiBCS (2006).

\begin{tabular}{cccc}
\hline Perfil & Classificação Solos & Perfil & Classificação Solos \\
\hline P01-LA & Latossolo Amarelo Distrófico, & P09-CX & Cambissolo Háplico Tb Distrófico \\
P02-CX & Cambissolo Háplico Alumínico, & P10-LA & Latossolo Amarelo Distrófico \\
P03-CX & Cambissolo Háplico Tb Distrófico & P11-PVA & Argissolo Vermelho Amarelo Alítico \\
P04-LV & Latossolo Vermelho Distrófico & P12-LA & Latossolo Amarelo Distrófico \\
P05-PV & Argissolo Vermelho Distrófico & P13-PVA & Argissolo Vermelho Amarelo Distrófico \\
P06-CX & Cambissolo Háplico Alumínico & P14-CX & Cambissolo Háplico Tb Distrófico \\
P07-PA & Argissolo Amarelo Distrófico & P15-LV a & Latossolo Vermelho Distrófico \\
P08-CX & Cambissolo Háplico Alumínico & P16-CX & Cambissolo Háplico Tb Distrófico \\
\hline
\end{tabular}

Em que: ${ }^{a}$ Área de referência com cobertura de pastagem; ${ }^{b}$ Área de referência com Mata. 
TABELA 2: Características morfológicas de alguns horizontes dos perfis de Latossolos sob SAFs do Projeto RECA, pastagem e floresta Amazônica, em Nova Califórnia - RO.

TABLE 2: Morphological characteristics of some horizons of the Oxisols under agroforestry systems of RECA project, pasture, and Amazon forest in Nova Califórnia - RO state.

\begin{tabular}{|c|c|c|c|c|c|c|}
\hline $\begin{array}{l}\text { Ident./ } \\
\text { Classe }\end{array}$ & $\begin{array}{l}\text { Horiz./ Prof. } \\
\qquad(\mathrm{cm})\end{array}$ & Cor $^{1}$ & $\begin{array}{l}\text { Mosqueado } \\
\text { Cor }\end{array}$ & Estrutura $^{3}$ & Consistência $^{4}$ & Tran-sição ${ }^{5}$ \\
\hline \multirow{3}{*}{ P01- LA } & A $/ 0-8$ & 7,5YR 3/4 & & $\mathrm{mo} / \mathrm{pe} / \mathrm{gr}$ & $\mathrm{ma} / \mathrm{mfr} / \mathrm{ppl} / \mathrm{peg}$ & $\mathrm{pl} / \mathrm{grd}$ \\
\hline & Bw2 /35-77 & 7,5 YR $5 / 4$ & & $\mathrm{fra} / \mathrm{pe} / \mathrm{gr}$ & $\operatorname{lgd} / \mathrm{mfr} / \mathrm{pl} / \mathrm{peg}$ & pl dif \\
\hline & Bw3 /77-130+ & 7,5YR 5/6 & & fra/pe/gr & $\operatorname{lgd} / \mathrm{mfr} / \mathrm{pl} / \mathrm{peg}$ & \\
\hline \multirow{4}{*}{ P04-LV } & $\mathrm{A} / 0-7$ & $2,5 \mathrm{YR} 4 / 4$ & & $\mathrm{mo} / \mathrm{pe} / \mathrm{sub}$ & $\mathrm{mdu} / \mathrm{fr} / \mathrm{pl} / \mathrm{peg}$ & $\mathrm{pl} / \mathrm{grd}$ \\
\hline & $\mathrm{BA} / 7-18$ & $2,5 \mathrm{YR} 4 / 6$ & & $\mathrm{mo} / \mathrm{pe} / \mathrm{sub}$ & $\mathrm{mdu} / \mathrm{fr} / \mathrm{pl} / \mathrm{peg}$ & $\mathrm{pl} / \mathrm{dif}$ \\
\hline & Bw2 /35-55 & 10R 4/8 & & $\mathrm{fr} / \mathrm{pe} / \mathrm{sub}$ & $\mathrm{ma} / \mathrm{fr} / \mathrm{pl} / \mathrm{peg}$ & $\mathrm{pl} / \mathrm{dif}$ \\
\hline & Bw5 /89-160+ & 10R 5/8 & & $\mathrm{mo} / \mathrm{pe} / \mathrm{sub}$ & $\mathrm{ma} / \mathrm{fr} / \mathrm{pl} / \mathrm{peg}$ & \\
\hline \multirow{4}{*}{ P15- LV } & $\mathrm{A} / 0-7$ & $2,5 \mathrm{YR} 4 / 2$ & $10 \mathrm{YR} 6 / 3 \mathrm{po} / \mathrm{pe} / \mathrm{pr}$ & $\mathrm{mo} / \mathrm{pe} / \mathrm{gr}$ & $\mathrm{ma} / \mathrm{fr} / \mathrm{lpl} / \mathrm{peg}$ & $\mathrm{pl} / \mathrm{cl}$ \\
\hline & $\mathrm{AB} / 7-22$ & $2,5 \mathrm{YR} 4 / 4$ & & $\mathrm{mo} / \mathrm{pe} / \mathrm{sub}$ & $\mathrm{ma} / \mathrm{fr} / \mathrm{pl} / \mathrm{peg}$ & $\mathrm{pl} / \mathrm{cl}$ \\
\hline & Bw1 /46-82 & 2,5YR 5/6 & & $\mathrm{fr} / \mathrm{me} / \mathrm{sub}$ & $\mathrm{ma} / \mathrm{fr} / \mathrm{pl} / \mathrm{peg}$ & $\mathrm{pl} / \mathrm{dif}$ \\
\hline & Bw2 /82-130+ & $2,5 \mathrm{YR} 5 / 8$ & & $\mathrm{fr} / \mathrm{me} / \mathrm{sub}$ & $\mathrm{ma} / \mathrm{fr} / \mathrm{pl} / \mathrm{peg}$ & \\
\hline \multirow{2}{*}{ P12- LA } & $\mathrm{A} / 0-10 / 15$ & 7,5 YR $3 / 4$ & & $\mathrm{mo} / \mathrm{me} / \mathrm{gr}$ & $\mathrm{ma} / \mathrm{fr} / \mathrm{mpl} / \mathrm{peg}$ & ond/cl \\
\hline & $\mathrm{Bw} / 35-135$ & 7,5 YR $5 / 6$ & & $\mathrm{mo} / \mathrm{pe} / \mathrm{sub}$ & $\operatorname{lgd} / \mathrm{fr} / \mathrm{mpl} / \mathrm{peg}$ & \\
\hline \multirow{4}{*}{ P10- LA } & $\mathrm{A} / 0-3$ & 10YR 3/1 & & $\mathrm{fr} / \mathrm{pe} / \mathrm{gr}$ & $\mathrm{mdu} / \mathrm{fr} / \mathrm{pl} / \mathrm{peg}$ & $\mathrm{pl} / \mathrm{abr}$ \\
\hline & $\mathrm{BA} / 3-10$ & 7,5 YR $5 / 4$ & & $\mathrm{mo} / \mathrm{pe} / \mathrm{sub}$ & $\mathrm{mdu} / \mathrm{fr} / \mathrm{pl} / \mathrm{peg}$ & $\mathrm{pl} / \mathrm{dif}$ \\
\hline & Bw2/42-78 & 7,5 YR $7 / 4$ & & $\mathrm{fr} / \mathrm{pe} / \mathrm{sub}$ & $\mathrm{du} / \mathrm{fr} / \mathrm{pl} / \mathrm{peg}$ & $\mathrm{pl} /$ dif \\
\hline & Bw3 /78-95 & 7,5 YR $7 / 4$ & & $\mathrm{fr} / \mathrm{pe} / \mathrm{sub}$ & $\mathrm{du} / \mathrm{mfr} / \mathrm{pl} / \mathrm{peg}$ & $\mathrm{pl} / \mathrm{dif}$ \\
\hline
\end{tabular}

Em que: ${ }^{1}$ Cores descritas solo úmido (carta de Munsell) ${ }^{2}$ mosqueado: $\mathrm{po}=$ pouco, $\mathrm{co}=$ comum, $\mathrm{ab}=$ abundante; $\mathrm{pe}=$ pequena, $\mathrm{me}=$ média; dis $=$ distinto, $\mathrm{pr}=$ proeminente, dif $=$ difuso ${ }^{3}$ estrutura: $\mathrm{fr} .=$ fraca; mo. $=$ moderada; fo. $=$ forte; $\mathrm{mp} .=$ muito pequena;pe $=$ pequena; me $=$ média; gr. $=$ granular; ang. $=$ blocos angulares; sub. $=$ blocos subangulares; mac $=$ maciça.${ }^{4}$ consistência: $\mathrm{ma} .=$ macia; $\operatorname{lgd} .=$ ligeiramente dura, $\mathrm{du}=\mathrm{dura}, \mathrm{mdu}=$ muito dura; $\mathrm{mfr} .=$ muito friável; $\mathrm{fr}=$ friável $\mathrm{ppl}=$ pouco plástico, lpl.= ligeiramente plástico,pl = plástico; ppeg.= pouco pegajoso, peg = pegajoso. ${ }^{5}$ Transição: $\mathrm{pl}=$ plana, ond $=$ ondulada; $\mathrm{abr}=$ abrupta, $\mathrm{cl}=$ clara, grd $=$ gradual, dif $=$ difusa .

TABELA 3: Características morfológicas de alguns horizontes dos perfis Cambissolos sob SAFs do Projeto RECA, pastagem e floresta Amazônica, em Nova Califórnia - RO.

TABLE 3: Morphological characteristics of some horizons of the Inceptisols under agroforestry systems of RECA project, pasture, and Amazon forest in Nova Califórnia - RO state.

\begin{tabular}{|c|c|c|c|c|c|c|c|}
\hline \multirow{2}{*}{$\begin{array}{l}\text { Ident./ } \\
\text { Classe }\end{array}$} & \multirow{2}{*}{$\begin{array}{l}\text { Horiz./ Prof. } \\
\quad(\mathrm{cm})\end{array}$} & \multirow{2}{*}{ Cor $^{1}$} & \multicolumn{2}{|c|}{ Mosqueado $^{2}$} & \multirow{2}{*}{ Estrutura $^{3}$} & \multirow{2}{*}{ Consistência ${ }^{4}$} & \multirow{2}{*}{ Transição } \\
\hline & & & Cor & & & & \\
\hline \multirow{4}{*}{ P02- CX } & A / $0-6$ & 7,5 YR 4/4 & & & $\mathrm{mo} / \mathrm{pe} / \mathrm{gr}$ & $\operatorname{lgd} /$ fr/pl/peg & pl grd \\
\hline & $\mathrm{Bi} 1 / 25-52$ & 5YR 4/6 & $10 \mathrm{YR} 7 / 3$ & $\mathrm{co} / \mathrm{pe} / \mathrm{dis}$ & $\mathrm{fr} / \mathrm{pe} / \mathrm{sub}$ & $\mathrm{du} / \mathrm{fr} / \mathrm{pl} / \mathrm{peg}$ & pl grd \\
\hline & $\mathrm{Bi} 2 / 52-88$ & $10 Y R 7 / 3$ & $2,5 \mathrm{YR} 4 / 6$ & $\mathrm{ab} / \mathrm{me} / \mathrm{dis}$ & $\mathrm{fr} / \mathrm{pe} / \mathrm{sub}$ & $\mathrm{du} / \mathrm{fr} / \mathrm{pl} / \mathrm{peg}$ & pl grd \\
\hline & $\mathrm{C} / 110-130+$ & N 6/ & 10YR 7/3 & $\mathrm{ab} / \mathrm{me}$ dis & Mac & $\mathrm{pl} / \mathrm{peg}$ & \\
\hline \multirow{4}{*}{ P03- CX } & $\mathrm{A} / 0-7$ & $5 Y R 4 / 2$ & & & fo/pe/sub & $\mathrm{ma} / \mathrm{fr} / \mathrm{pl} / \mathrm{peg}$ & $\mathrm{pl} /$ grd \\
\hline & Bi1 /16-35 & 5YR 5/6 & & & fo/pe/sub & mdua/fr/pl/peg & $\mathrm{pl} /$ dif \\
\hline & $\mathrm{Bi2} / 35 / 64$ & 7,5YR 5/6 & & & $\mathrm{mo} / \mathrm{pe} / \mathrm{sub}$ & $\mathrm{du} / \mathrm{fr} / \mathrm{pl} / \mathrm{peg}$ & $\mathrm{pl} / \mathrm{abr}$ \\
\hline & C /64-120+ & $2,5 \mathrm{YR} 4 / 4$ & $5 Y 8 / 6$ & $\mathrm{ab} / \mathrm{gr} / \mathrm{pr}$ & & & \\
\hline
\end{tabular}


TABELA 3: Continuação...

TABLE 3: Continued...

\begin{tabular}{|c|c|c|c|c|c|c|c|}
\hline \multirow{2}{*}{$\begin{array}{l}\text { Ident./ } \\
\text { Classe }\end{array}$} & \multirow{2}{*}{$\begin{array}{l}\text { Horiz./ Prof. } \\
\quad(\mathrm{cm})\end{array}$} & \multirow{2}{*}{ Cor $^{1}$} & \multicolumn{2}{|c|}{ Mosqueado $^{2}$} & \multirow{2}{*}{ Estrutura $^{3}$} & \multirow{2}{*}{ Consistência ${ }^{4}$} & \multirow{2}{*}{ Transição $^{5}$} \\
\hline & & & Cor & & & & \\
\hline \multirow{4}{*}{ P 06- CX } & A /0-6 & 7,5YR 4/2 & & & fo/me/gr & $\mathrm{ma} / \mathrm{fr} / \mathrm{pl} / \mathrm{peg}$ & $\mathrm{pl} / \mathrm{cl}$ \\
\hline & $\mathrm{AB} / 6-25$ & 7,5YR 5/4 & & & $\mathrm{mo} / \mathrm{pe} / \mathrm{sub}$ & $\mathrm{ma} / \mathrm{fr} / \mathrm{pl} / \mathrm{peg}$ & pl grd \\
\hline & $\mathrm{Bi} / 44-65$ & 5YR 5/6 & 10YR 6/4 & $\mathrm{ab} / \mathrm{me} / \mathrm{dis}$ & $\mathrm{fr} / \mathrm{me} / \mathrm{sub}$ & $\mathrm{du} / \mathrm{mfr} / \mathrm{ppl} / \mathrm{peg}$ & $\mathrm{pl} / \mathrm{grd}$ \\
\hline & $\mathrm{BC} / 65-89$ & $5 \mathrm{YR} 5 / 6$ & 10YR 6/4 & $\mathrm{ab} / \mathrm{me} / \mathrm{dis}$ & & $\mathrm{ppl} / \mathrm{ppeg}$ & $\mathrm{pl} / \mathrm{grd}$ \\
\hline \multirow{4}{*}{ P08- CX } & $\mathrm{A} / 0-6$ & $5 Y R 4 / 3$ & & & $\mathrm{mo} / \mathrm{pe} / \mathrm{gr}$ & & \\
\hline & $\mathrm{AB} / 6-14$ & 5YR 5/4 & & & $\mathrm{mo} / \mathrm{pe} / \mathrm{sub}$ & $\mathrm{ma} / \mathrm{fr} / \mathrm{pl} / \mathrm{peg}$ & $\mathrm{pl} / \mathrm{cl}$ \\
\hline & Bi1 /14-27 & 5YR 6/4 & & & $\mathrm{mo} / \mathrm{pe} / \mathrm{sub}$ & $\mathrm{ma} / \mathrm{fr} / \mathrm{pl} / \mathrm{peg}$ & $\mathrm{pl} / \mathrm{cl}$ \\
\hline & $\mathrm{C} / 55-120+$ & 2,5YR 5/8 & 10YR 6/8 & $\mathrm{ab} / \mathrm{pe} /$ & mac & $\mathrm{ma} / \mathrm{fr} / \mathrm{pl} / \mathrm{peg}$ & $\mathrm{pl} / \mathrm{dif}$ \\
\hline \multirow{4}{*}{ P09- CX } & A /0-3 & 5YR 4/1 & & & $\mathrm{fr} / \mathrm{pe} / \mathrm{sub}$ & $\mathrm{du} / \mathrm{fr} / \mathrm{pl} / \mathrm{peg}$ & $\mathrm{pl} / \mathrm{abr}$ \\
\hline & $\mathrm{Bi} / 3-32$ & 5YR 5/8 & N 6/ & $\mathrm{co} / \mathrm{pe} /$ & $\mathrm{fr} / \mathrm{pe} / \mathrm{sub}$ & $\mathrm{du} / \mathrm{fr} / \mathrm{pl} / \mathrm{peg}$ & $\mathrm{pl} /$ dif \\
\hline & $\mathrm{BC} / 32-53$ & 5YR 5/6 & 10YR 6/4 & $\mathrm{ab} / \mathrm{me} /$ & mac & $\mathrm{pl} / \mathrm{peg}$ & $\mathrm{pl} / \mathrm{dif}$ \\
\hline & $\mathrm{C} / 53-100$ & $2,5 \mathrm{YR} 4 / 6$ & 10YR 6/4 & $\mathrm{ab} / \mathrm{me} /$ & mac & $\mathrm{pl} / \mathrm{peg}$ & \\
\hline \multirow{3}{*}{ P14 - CX } & $\mathrm{A} / 0-8$ & 7,5YR 4/2 & & & $\mathrm{mo} / \mathrm{me} / \mathrm{gr}$ & $\mathrm{ma} / \mathrm{fr} / \mathrm{pl} / \mathrm{peg}$ & $\mathrm{pl} / \mathrm{cl}$ \\
\hline & BA/8-22 & $7,5 Y R$ 4/6 & & & $\mathrm{fr} / \mathrm{pe} / \mathrm{sub}$ & $\mathrm{du} / \mathrm{fr} / \mathrm{pl} / \mathrm{peg}$ & $\mathrm{pl} /$ dif \\
\hline & $\mathrm{Bi} 2 / 41-71$ & 5YR 5/6 & & & $\mathrm{fr} / \mathrm{pe} / \mathrm{sub}$ & $\mathrm{ma} / \mathrm{pfr} / \mathrm{pl} / \mathrm{peg}$ & $\mathrm{pl} / \mathrm{dif}$ \\
\hline \multirow{6}{*}{ P16- CX } & $\mathrm{A} / 0-10$ & 7,5YR 5/2 & & & $\mathrm{fr} / \mathrm{me} / \mathrm{gr}$ & $\mathrm{ma} / \mathrm{fr} / \mathrm{ppl} / \mathrm{peg}$ & $\mathrm{pl} / \mathrm{grd}$ \\
\hline & $\mathrm{Bi1} / 58-70$ & 7,5YR 6/6 & & & $\mathrm{fr} / \mathrm{me} / \mathrm{sub}$ & $\mathrm{ma} / \mathrm{fr} / \mathrm{pl} / \mathrm{peg}$ & $\mathrm{pl} / \mathrm{abr}$ \\
\hline & $\mathrm{Bi} 2 / 70-100$ & 7,5YR 5/8 & $2,5 Y 7 / 4$ & $\mathrm{po} / \mathrm{pe} / \mathrm{pr}$ & $\mathrm{fr} / \mathrm{me} / \mathrm{sub}$ & $\mathrm{ma} / \mathrm{fr} / \mathrm{ppl} / \mathrm{peg}$ & $\mathrm{pl} / \mathrm{cl}$ \\
\hline & $\mathrm{BC}$ & $5 \mathrm{YR}$ & & & & & \\
\hline & & $5 / 82,5 \mathrm{Y}$ & & $\mathrm{ab} / \mathrm{me} / \mathrm{pr}$ & $\mathrm{fr} / \mathrm{me} / \mathrm{sub}$ & & \\
\hline & & $7 / 6$ & & & & & \\
\hline
\end{tabular}

Em que: ${ }^{1}$ Cores descritas solo úmido $\left(\right.$ carta de Munsell) ${ }^{2}$ mosqueado: po $=$ pouco, co $=$ comum, $a b=$ abundante; pe $=$ pequena, $\mathrm{me}=$ média; dis $=$ distinto, $\mathrm{pr}=$ proeminente, dif $=$ difuso. ${ }^{3}$ estrutura: fr. $=$ fraca; mo. $=$ moderada; fo. $=$ forte; $\mathrm{mp} .=$ muito pequena; pe.= pequena; me.= média; gr.= granular; ang.= blocos angulares; sub.= blocos subangulares; mac $=$ maciça.${ }^{4}$ consistência: ma. $=$ macia; lgd. = ligeiramente dura, du = dura, $\mathrm{mdu}=$ muito dura; mfr.= muito friável; $\mathrm{fr}=$ friável $\mathrm{ppl}=$ pouco plástico, $\mathrm{lpl} .=$ ligeiramente plástico, $\mathrm{pl}=$ plástico; ppeg. $=$ pouco pegajoso, peg $=$ pegajoso. ${ }^{5}$ Transição: $\mathrm{pl}=$ plana, ond = ondulada; $\mathrm{abr}=$ abrupta, $\mathrm{cl}=$ clara, grd = gradual, $\operatorname{dif}=$ difusa.

TABELA 4: Características morfológicas de alguns horizontes dos perfis de Argissolos sob SAFs do Projeto RECA, pastagem e floresta Amazônica, em Nova Califórnia - RO.

TABLE 4: Morphological characteristics of some horizons of the Ultisols under agroforestry systems of RECA project, pasture, and Amazon forest in Nova Califórnia - RO state.

\begin{tabular}{|c|c|c|c|c|c|c|c|}
\hline \multirow{2}{*}{$\begin{array}{l}\text { Ident./ } \\
\text { Classe }\end{array}$} & \multirow{2}{*}{$\begin{array}{l}\text { Horiz./ Prof. } \\
\quad(\mathrm{cm})\end{array}$} & \multirow[b]{2}{*}{ Cor $^{1}$} & \multicolumn{2}{|c|}{ Mosqueado $^{2}$} & \multirow{2}{*}{ Estrutura $^{3}$} & \multirow{2}{*}{ Consistência $^{4}$} & \multirow{2}{*}{ Transição } \\
\hline & & & Cor & & & & \\
\hline \multirow{4}{*}{ P05-PV } & A $/ 0-6$ & $5 \mathrm{YR} 4 / 2$ & & & $\mathrm{mo} / \mathrm{mp} / \mathrm{sub}$ & $\mathrm{ma} / \mathrm{fr} / \mathrm{pl} / \mathrm{peg}$ & $\mathrm{pl} \mathrm{cl}$ \\
\hline & Bt1 /16-40 & $2,5 Y R 5 / 6$ & & & $\mathrm{mo} / \mathrm{pe} / \mathrm{sub}$ & $\mathrm{du} / \mathrm{fr} / \mathrm{pl} / \mathrm{peg}$ & $\mathrm{pl} / \mathrm{dif}$ \\
\hline & Bt2 /40-70 & $2,5 \mathrm{YR} 5 / 6$ & $\begin{array}{c}7,5 \mathrm{YR} \\
5 / 6\end{array}$ & $\mathrm{po} / \mathrm{pe} / \mathrm{dis}$ & $\mathrm{fr} / \mathrm{pe} / \mathrm{sub}$ & $\mathrm{du} / \mathrm{fr} / \mathrm{pl} /$ peg & $\mathrm{pl} /$ dif \\
\hline & $\mathrm{BC} / 70-120+$ & $2,5 \mathrm{YR} 5 / 8$ & $\begin{array}{c}7,5 \mathrm{YR} \\
5 / 6\end{array}$ & $\mathrm{po} / \mathrm{pe} / \mathrm{dis}$ & & & \\
\hline
\end{tabular}


TABELA 4: Continuação...

TABLE 4: Continued...

\begin{tabular}{|c|c|c|c|c|c|c|c|}
\hline \multirow{2}{*}{$\begin{array}{l}\text { Ident./ } \\
\text { Classe }\end{array}$} & \multirow{2}{*}{$\begin{array}{l}\text { Horiz./ Prof. } \\
\qquad(\mathrm{cm})\end{array}$} & \multirow{2}{*}{ Cor $^{1}$} & \multicolumn{2}{|c|}{ Mosqueado $^{2}$} & \multirow{2}{*}{ Estrutura $^{3}$} & \multirow{2}{*}{ Consistência $^{4}$} & \multirow{2}{*}{ Transição } \\
\hline & & & Cor & & & & \\
\hline \multirow{4}{*}{ P07-PA } & $\mathrm{A} / 0-4$ & $10 \mathrm{YR} 5 / 2$ & & & $\mathrm{mo} / \mathrm{pe} / \mathrm{sub}$ & $\underset{\text { npeg }}{\mathrm{ma} / \mathrm{mfr} / \mathrm{npl} /}$ & $\mathrm{pl} / \mathrm{grd}$ \\
\hline & $\mathrm{Bt} / 40-60$ & 10YR $7 / 4$ & & & $\mathrm{fr} / \mathrm{pe} / \mathrm{sub}$ & $\mathrm{du} / \mathrm{mfr} / \mathrm{lpl} / \mathrm{npeg}$ & $\mathrm{pl} / \mathrm{grd}$ \\
\hline & $\mathrm{BC} / 60-78$ & 10YR $7 / 4$ & $\begin{array}{c}2,5 \mathrm{YR} \\
5 / 6\end{array}$ & $\mathrm{ab} / \mathrm{me} / \mathrm{pr}$ & $\mathrm{fr} / \mathrm{pe} / \mathrm{sub}$ & & $\mathrm{pl} / \mathrm{cl}$ \\
\hline & $\mathrm{C} / 78-130+$ & $10 \mathrm{YR} 6 / 3$ & $\begin{array}{c}2,5 \mathrm{YR} \\
4 / 8\end{array}$ & $\mathrm{ab} / \mathrm{me} / \mathrm{pr}$ & $\mathrm{fr} / \mathrm{pe} / \mathrm{sub}$ & & \\
\hline \multirow{4}{*}{ P11-PVA } & A/0-6 & $7,5 \mathrm{YR} 4 / 4$ & & & fo/pe/gr & $\operatorname{lgd} / \mathrm{fr} / \mathrm{pl} / \mathrm{peg}$ & $\mathrm{pl} / \mathrm{cl}$ \\
\hline & Bt1 /39-57 & $5 Y R 5 / 6$ & & & $\mathrm{mo} / \mathrm{me} / \mathrm{ang}$ & $\operatorname{lgd} /$ fr/pl/peg & $\mathrm{pl} / \mathrm{grd}$ \\
\hline & Bt2 /57-80 & $5 Y R 6 / 6$ & $2,5 Y 7 / 4$ & $\mathrm{po} / \mathrm{pe} / \mathrm{dis}$ & mo/pe/ang & $\operatorname{lgd} /$ fr/pl/peg & $\mathrm{pl} / \mathrm{grd}$ \\
\hline & $\mathrm{BC} / 80-120+$ & $2,5 Y 7 / 4$ & $\begin{array}{c}2,5 \mathrm{YR} \\
5 / 6\end{array}$ & & mac & & \\
\hline \multirow{4}{*}{ P13-PVA } & $\mathrm{A} / 0-4$ & 5 YR $4 / 2$ & & & $\mathrm{mo} / \mathrm{me} / \mathrm{gr}$ & $\mathrm{ma} / \mathrm{fr} / \mathrm{pl} / \mathrm{peg}$ & $\mathrm{pl} / \mathrm{cl}$ \\
\hline & $\mathrm{BA} / 4-21$ & $5 Y R 4 / 4$ & & & fo/me/sub & $\mathrm{ma} / \mathrm{fr} / \mathrm{pl} / \mathrm{peg}$ & $\mathrm{pl} / \mathrm{dif}$ \\
\hline & $\mathrm{Bt} 1 / 21-52$ & 5YR 5/4 & & & $\mathrm{mo} / \mathrm{me} / \mathrm{sub}$ & $\mathrm{ma} / \mathrm{fr} / \mathrm{pl} / \mathrm{peg}$ & $\mathrm{pl} / \mathrm{dif}$ \\
\hline & $\mathrm{BC} / 90-120+$ & 5 YR $6 / 6$ & $2,5 Y 7 / 4$ & $\mathrm{ab} / \mathrm{pe} / \mathrm{pr}$ & $\mathrm{fr} / \mathrm{pe} / \mathrm{sub}$ & $\mathrm{ma} / \mathrm{fr} / \mathrm{pl} / \mathrm{peg}$ & \\
\hline
\end{tabular}

Em que: ${ }^{1}$ Cores descritas solo úmido (carta de Munsell) ${ }^{2}$ mosqueado: $p o=$ pouco, $c 0=$ comum, $a b=$ abundante; $p e=$ pequena, $\mathrm{me}=$ média; dis $=$ distinto, $\mathrm{pr}=$ proeminente, $\operatorname{dif}=$ difuso. ${ }^{3}$ estrutura: $\mathrm{fr} .=$ fraca; mo. $=$ moderada; fo. $=$ forte; $\mathrm{mp} .=$ muito pequena; pe. = pequena; me.= média; gr. = granular; ang. $=$ blocos angulares; sub. $=$ blocos subangulares; mac $=$ maciça.${ }^{4}$ consistência: ma. $=$ macia; lgd. $=$ ligeiramente dura, $\mathrm{du}=$ dura, $\mathrm{mdu}=$ muito dura; $\mathrm{mfr} .=$ muito friável; fr = friável $\mathrm{ppl}=$ pouco plástico, $1 \mathrm{pl}$.= ligeiramente plástico, $\mathrm{pl}=$ plástico; $\mathrm{npeg}=$ não pegajoso; ppeg.= pouco pegajoso, peg $=$ pegajoso.${ }^{5}$ Transição: $\mathrm{pl}=$ plana, ond $=$ ondulada; $\mathrm{abr}=$ abrupta, $\mathrm{cl}=$ clara, $\operatorname{grd}=$ gradual, $\operatorname{dif}=$ difusa .

A RMSP está intimamente relacionada ao teor de umidade do solo, sendo assim, os teores de umidade referentes a cada unidade amostral serão discutidos posteriormente.

As áreas de Latossolos (Figura 1) foram heterogêneas com variação da RMSP de 1,13 a 1,75 $\mathrm{MPa}$ na superfície. Esses valores enquadramse na classe sem restrição a penetração de raízes. À medida que se aprofunda no perfil a heterogeneidade se manteve, sendo possível identificar as três classes de resistência à penetração, como por exemplo, a área P10-LA, que em subsuperfície apresentou RMSP de 3,52 MPa.

Nos Cambissolos (Figura 1) os valores de RMSP variaram de 1,08 a 1,22 MPa em superfície; portanto, pertencendo à classe dos não restritivos. Os valores aumentaram nas camadas subsequentes, chegando até 2,96 $\mathrm{MPa}$ em subsuperfície, com aumento linear com a profundidade e sendo, em geral, classificados como restritivos. Na área P9CX foi obtido valor muito elevado de RMSP, de 4,59 $\mathrm{MPa}$, interpretado como devido à camada impeditiva. Esses valores mais altos podem ser explicados por adensamento nos próprios sedimentos de origem, o fator com maior influência na gênese dos Cambissolos. Nos Argissolos (Figura 1), a RMSP variou de menos que 0,96 a $1,91 \mathrm{MPa}$ em superfície, na qual todas as áreas estão na classe não restritiva. Nas camadas subsequentes, uma das áreas se mantém como não restritiva e as outras três aumentaram a RMSP de forma quase linear com o aumento da profundidade, passando para classe com algum impedimento de penetração das raízes. Para a área P7-PA foi observado decréscimo na RMSP nas primeiras camadas, logo abaixo da superfície, coincidindo com a descrição morfológica do perfil no qual foi identificado horizonte $\mathrm{E}$ com textura mais arenosa.

Entre as áreas de referência, os maiores valores de RMSP foram encontrados na pastagem (Figura 1), com RMSP na camada entre 15 e $30 \mathrm{~cm}$ acima dos valores críticos e dos encontrados para todas as áreas de SAF. Portanto, nas três ordens de solo, pelo menos uma das áreas indicou, com base 
nos valores críticos de referência, algum tipo de restrição à penetração das raízes e em duas das áreas (P9-CX e P10-LA) as restrições se mostraram mais severas. O que poderia tornar as culturas instaladas nos SAFs mais suscetíveis a períodos de seca ou de excesso de água e conferir menor capacidade de suporte, principalmente nas árvores de grande porte.

Nos solos estudados, os valores de RMSP variaram de 0,96 a 4,59 MPa. Enquanto Souza et al. (2006), avaliando cana-de-açúcar no município de Jaboticabal, encontraram valores entre 1,22 e 4,15 MPa. Por sua vez, Nascimento et al. (2007), na região de Goiânia, encontraram valores entre 2,34 a 11,95 MPa. Assim, observa-se grande variação de resultados, atribuídas às diferenças inerentes às classes de solos e aos manejos, porém, como os manejos das áreas de SAFs são muito semelhantes entre si, atribuem-se as variações verificadas no presente trabalho a fatores pedogenéticos, em especial ao material de origem, que é muito heterogêneo e que reflete nas características dos solos formados.

Os resultados da subtração dos valores de RMSP determinados nas áreas de SAFs e nas áreas de referência "MATA" e "PASTAGEM" são apresentados na Tabela 5. A comparação da RMSP tendo como referência a área de Mata indicou que sete das quatorze áreas de SAF apresentaram RMSP maiores (destaque em cinza na Tabela 5) desde as camadas superficiais, sendo que apenas três (P1-LA, $\mathrm{P} 7-\mathrm{PA}$ e $\mathrm{P} 8-\mathrm{CX}$ ) possuem valores menores ou iguais aos da área de referência, em toda a seção de solo avaliada. As áreas P2-CX, P5-PV, P6-CX e P11-PVA apresentaram menores RMSP até a profundidade de $30 \mathrm{~cm}$ e depois aumentaram. As áreas P3-CX, P4LV, P9-CX, P10-LA e P13-PVA mostraram valores de RMSP maiores em toda a seção avaliada, sendo a área P9-CX a que apresentou a maior diferença (valor de 2,5) para a mata. Observando a diferença nos valores de RMSP em relação a área de Pastagem, nota-se que nas maiores profundidades somente nas áreas P7-PA e P12-LA os valores de resistência à penetração foram menores ou iguais ao determinado na área de referência. Portanto, em profundidade, as demais áreas apresentaram RMSP maiores, chegando à diferença de 2,7 na área P9-CX. Para a camada superficial, as áreas P10-LA e P13-PVA também tiveram valores de RMSP superiores.

Amaral et al. (2004) avaliando Argissolos em Purus - AM encontraram valores de RMSP entre 0,6 e 1,6 MPa na camada superficial $(0-20 \mathrm{~cm})$ e 1,2 a 2,6 MPa na subsuperficial $(20-40 \mathrm{~cm})$, sendo os menores valores encontrados sob mata de pupunha e os maiores sob pastagem. A umidade do solo variou entre 20 e $24 \%$.

Os teores de umidade variaram entre os perfis e foram maiores nos Latossolos (Figura 2), os quais tiveram os menores valores de RMSP.
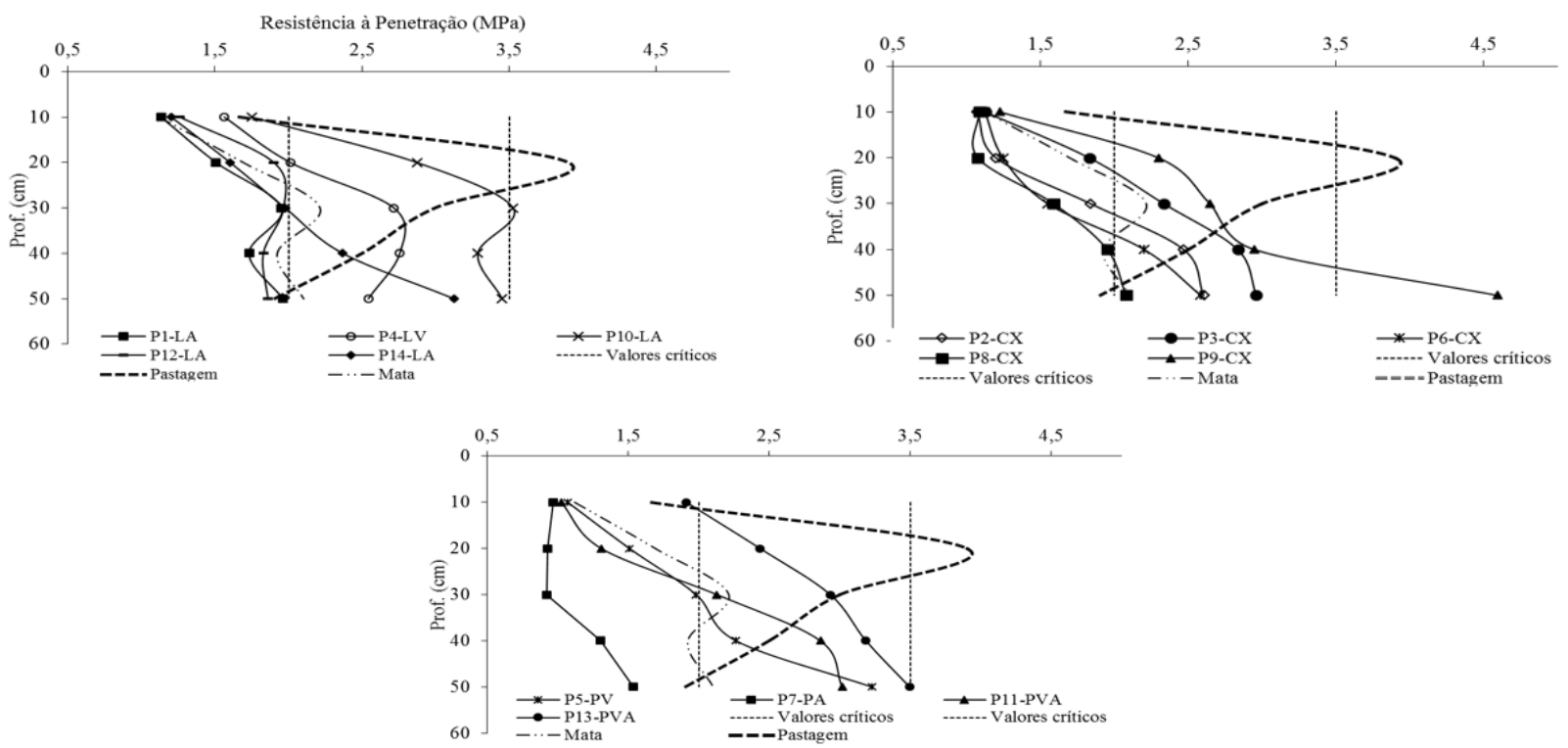

FIGURA 1: Valores de resistência à penetração em Latossolos (L), Cambissolos $(\mathrm{C})$ e Argissolos (P), em áreas de SAFs no RECA e em pastagem e mata, em Nova Califórnia - RO.

FIGURE 1: Values of resistance to penetration in Oxisols (L), Inceptisols (C), and Ultisols (A) under agroforestry systems of RECA project, pasture and Amazon forest in Nova Califórnia - RO. 
TABELA 5: Diferença em profundidade $(\mathrm{cm})$ entre os valores de resistência à penetração de cada SAF no RECA em relação às áreas de referência (PASTAGEM e MATA).

TABLE 5: Differences among values of resistance to penetration of each area and depth $(\mathrm{cm})$ and the reference areas (pasture and Forest).

\begin{tabular}{ccccccccccccccc}
\hline \multicolumn{11}{c}{ PASTAGEM } \\
\hline Prof. & P1- & P2- & P3- & P4- & P5- & P6- & P7- & P8- & P9- & P10- & P11- & P12- & P13- & P14- \\
& LA & CX & CX & LV & PV & CX & PA & CX & CX & LA & PVA & LA & PVA & CX \\
$0-10$ & $-0,5$ & $-0,6$ & $-0,5$ & $-0,1$ & $-0,6$ & $-0,5$ & $-0,7$ & $-0,6$ & $-0,4$ & 0,1 & $-0,6$ & $-0,4$ & 0,2 & $-0,5$ \\
-20 & $-2,4$ & $-2,7$ & $-2,1$ & $-1,9$ & $-2,4$ & $-2,7$ & $-3,0$ & $-2,8$ & $-1,6$ & $-1,0$ & $-2,6$ & $-2,0$ & $-1,5$ & $-2,3$ \\
-30 & $-1,0$ & $-1,2$ & $-0,7$ & $-0,3$ & $-1,0$ & $-1,5$ & $-2,1$ & $-1,4$ & $-0,4$ & 0,5 & $-0,9$ & $-1,0$ & $-0,1$ & $-1,0$ \\
-40 & $-0,8$ & 0,0 & 0,3 & 0,3 & $-0,2$ & $-0,3$ & $-1,2$ & $-0,6$ & 0,4 & 0,8 & 0,4 & $-0,7$ & 0,7 & $-0,1$ \\
-50 & 0,1 & 0,7 & 1,1 & 0,6 & 1,3 & 0,7 & $-0,4$ & 0,2 & 2,7 & 1,5 & 1,1 & 0,0 & 1,6 & 1,2 \\
& & & & & & & MATA & & & & & & \\
& P1- & P2- & P3- & P4- & P5- & P6- & P7- & P8- & P9- & P10- & P11- & P12- & P13- & P14- \\
Prof. & LA & CX & CX & LV & PV & CX & PA & CX & CX & LA & PVA & LA & PVA & CX \\
$0-10$ & 0,0 & $-0,1$ & 0,0 & 0,4 & 0,0 & 0,0 & $-0,2$ & 0,0 & 0,1 & 0,6 & $-0,1$ & 0,1 & 0,8 & 0,1 \\
-20 & $-0,2$ & $-0,5$ & 0,1 & 0,3 & $-0,2$ & $-0,4$ & $-0,8$ & $-0,6$ & 0,6 & 1,2 & $-0,4$ & 0,2 & 0,7 & $-0,1$ \\
-30 & $-0,3$ & $-0,4$ & 0,1 & 0,5 & $-0,2$ & $-0,7$ & $-1,3$ & $-0,6$ & 0,4 & 1,3 & $-0,1$ & $-0,2$ & 0,7 & $-0,2$ \\
-40 & $-0,2$ & 0,5 & 0,9 & 0,8 & 0,3 & 0,3 & $-0,6$ & 0,0 & 1,0 & 1,4 & 0,9 & $-0,1$ & 1,3 & 0,4 \\
-50 & $-0,1$ & 0,5 & 0,9 & 0,4 & 1,1 & 0,5 & $-0,6$ & 0,0 & 2,5 & 1,3 & 0,9 & $-0,2$ & 1,4 & 1,0 \\
\hline
\end{tabular}

Em que: Valores positivos (destaque em cinza) representam valores de RMSP maiores que as áreas de referência.

Esse resultado pode ser explicado pelo maior grau de desenvolvimento desses solos, ou seja, melhor agregação e, com isso, aumento da capacidade de retenção de água e da porosidade. Como as coletas foram feitas no mesmo período do ano, as variações da umidade do solo refletem propriedades dos solos. Corroborando esses resultados, os valores de densidade do solo (Figura 3) foram menores nas áreas sob Latossolo refletindo a melhor agregação (Tabela 2) desses solos em relação aos demais.

Os resultados de densidade do solo foram semelhantes aos observados por Ribon et al. (2003) e seguiram comportamento similar ao dos valores de RMSP. As áreas com menores valores de Ds também foram as áreas com menor RMSP, com os maiores valores nos Cambissolos, em uma relação direta entre densidade do solo e a resistencia à penetração. Como as áreas dos SAFs não têm tráfego de implementos e maquinários, que poderiam causar a compactação dos solos, infere-se que as variações se devem aos processos pedogenéticos. Além disso, observa-se aumento da RMSP com a profundidade do solo, indicando maior influência da sedimentação do material de origem da Formação Solimões, em detrimento de efeito de manejo dado às terras.

\section{Estoques de carbono dos solos e análise de componentes principais}

Os estoques de carbono do solo (Figura 4) mostraram variação aleatória com as classes de solo. Nas áreas de Latossolos, os valores foram mais homogêneos variando de 45,19 a $88,70 \mathrm{Mg}$ $\mathrm{C}$ ha $^{-1}$. Nas áreas de Cambissolos e de Argissolos foi observada maior variação nos estoques de $\mathrm{C}$, de 45,84 a $100,60 \mathrm{Mg} \mathrm{C}$ ha $^{-1}$, e de 47,55 até 126,04 $\mathrm{Mg} \mathrm{C} \mathrm{ha-1}$, respectivamente. As áreas de referência sob cobertura de pastagem e mata apresentaram respectivamente 72,79 e 70,04 $\mathrm{Mg} \mathrm{C}^{-1}$ (Tabela 4).

Os valores de estoque de $\mathrm{C}$ foram maiores que os de Araújo et al. (2011), em duas áreas com diferentes tipos de usos, sendo uma sob um Argissolo Vermelho Amarelo Alítico Plíntico no município de Rio Branco - AC e outra de Latossolo Vermelho Amarelo Distrófico, em Senador Guiomar - AC. Esses autores encontraram variações de 4,77 a 22,86 Mg C ha ${ }^{-1}$. Já no bioma cerrado, em Latossolo Vermelho Distroférrico típico, Rangel \& Silva (2007) encontraram estoques de 90,6 e 94,6 $\mathrm{Mg} \mathrm{C} \mathrm{ha}{ }^{-1}$ para mata e pastagem, respectivamente; e D'Andréa et al. (2004) observaram estoques de 61,10 e $69,86 \mathrm{Mg} \mathrm{C} \mathrm{ha}^{-1}$ em Cerrado e pastagem.

$\mathrm{O}$ estoque de $\mathrm{C}$ pouco diferiu entre as áreas 

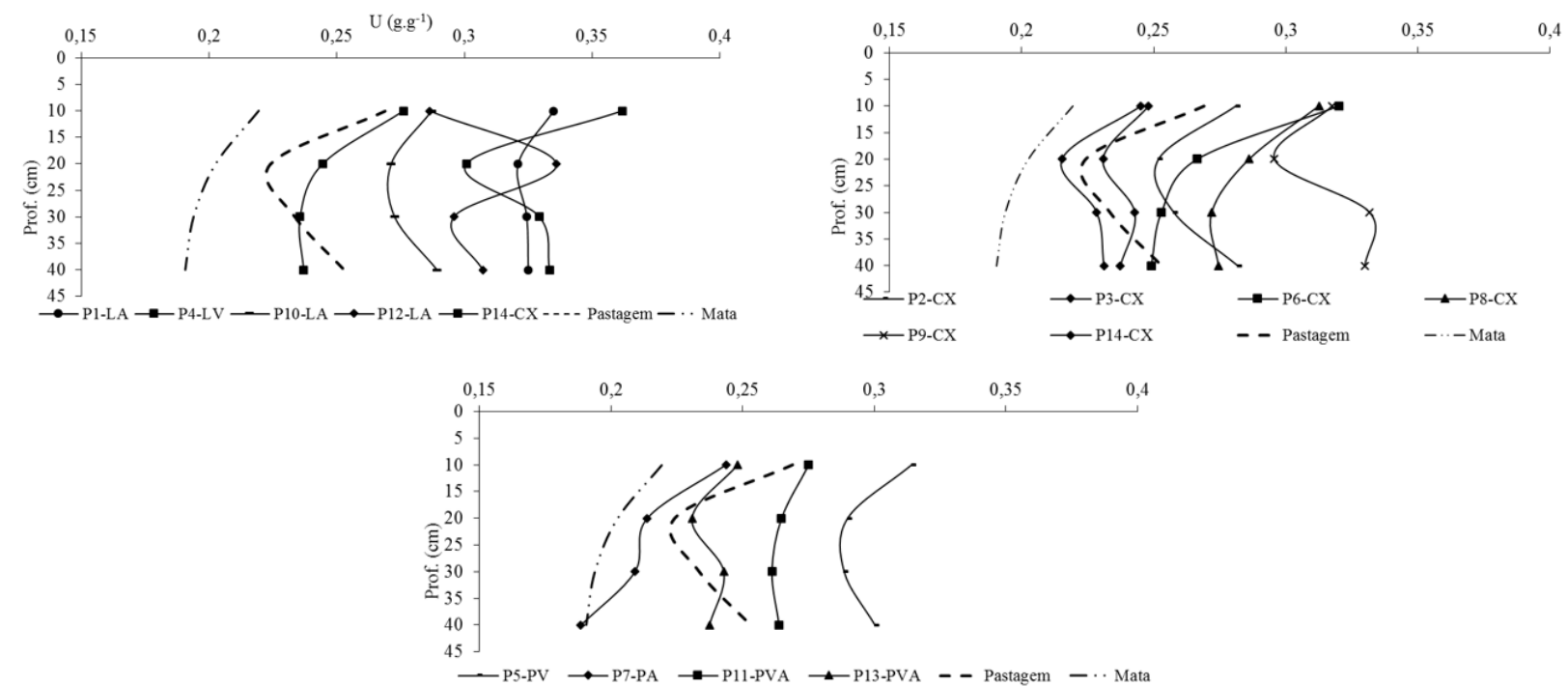

FIGURA 2: Teor de umidade do solo ( $\left.\mathrm{g} \mathrm{g}^{-1}\right)$ em Latossolos (L), Cambissolos (C) e Argissolos (P) em áreas de SAFs no RECA e em pastagem e mata, em Nova Califórnia - RO.

FIGURE 2: Moisture content (g.g $\left.\mathrm{g}^{-1}\right)$ in Oxisols (L), Inceptisols (C), and Ultisols (A) under agroforestry systems of RECA project, pasture and Amazon forest in Nova Califórnia - RO state.
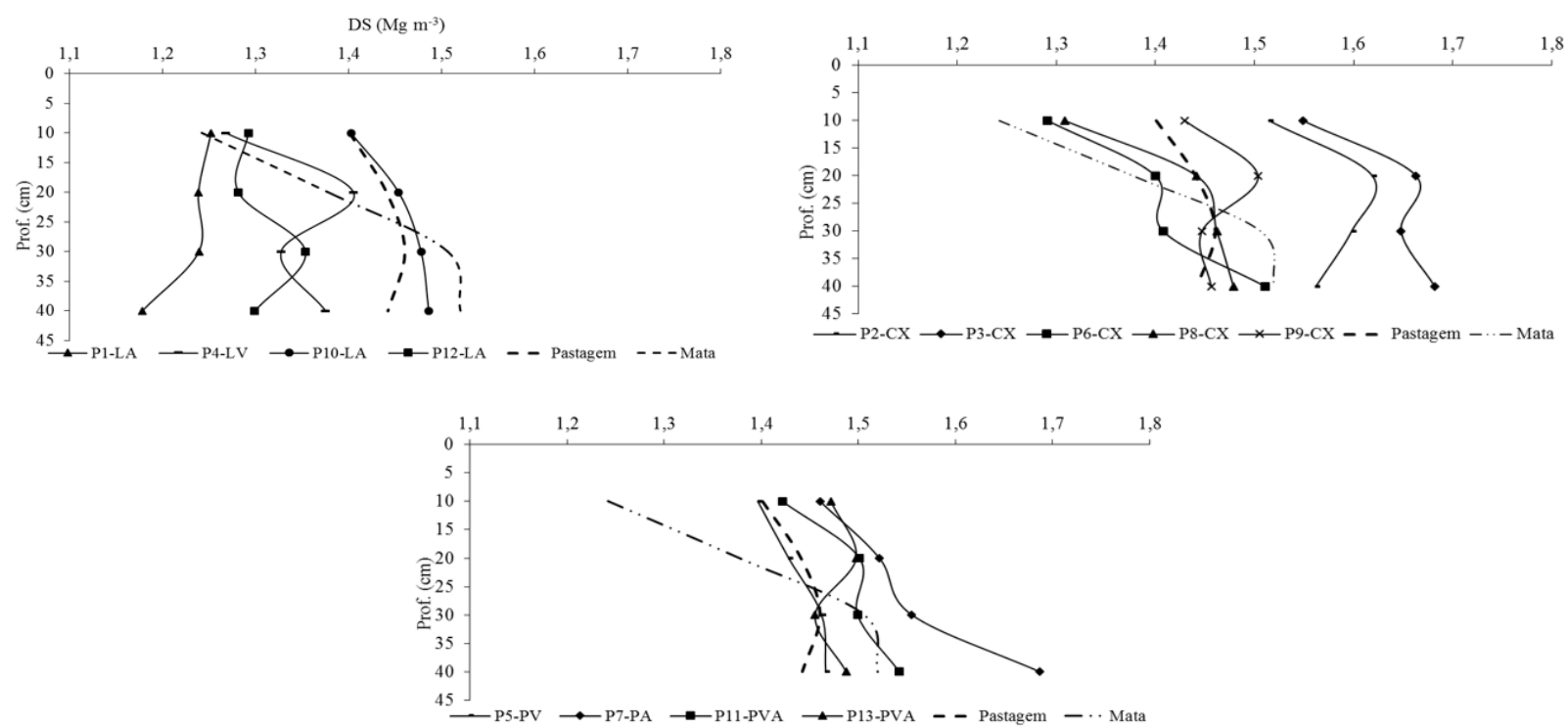

FIGURA 3: Valores de densidade do solo (Ds) em Latossolos (L), Cambissolos (C) e Argissolos (P), em áreas de SAFs no RECA e em pastagem e mata, em Nova Califórnia - RO.

FIGURE 3: Bulk density (Ds) in Oxisols (L), Inceptisols (C), and Ultisols (A) under agroforestry systems of RECA project, pasture and Amazon forest in Nova Califórnia - RO state.

de referência. Se comparadas às áreas de Mata e Pastagem e as de SAF, nota-se que 5 dos 14 SAFs tiveram maiores estoques de C (P10-LA e P12-LA; P8-CX e P14-CX; e P13-PVA) e, em duas áreas, os valores são muito próximos (P4-LV e P9-CX). Assim, para cerca de metade das áreas de SAF, os estoques de $\mathrm{C}$ são mantidos ou até aumentam em relação à área de referência com mata, indicando que estes sistemas são relevantes para manutenção da matéria orgânica do solo.

A avaliação dos atributos químicos e da granulometria das áreas de SAFs e as de referência pela análise de componentes principais (ACP) na profundidade de $0-20 \mathrm{~cm}$ (Figura 5) mostra que as duas áreas (PASTAGEM e MATA) não diferiram significativamente, estando agrupadas 


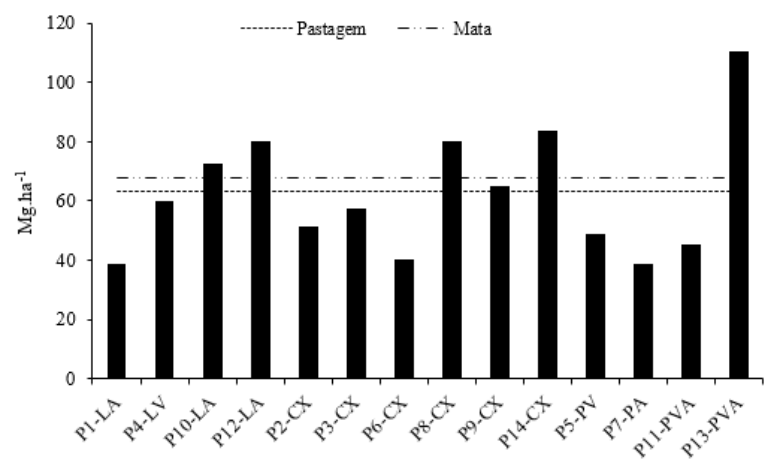

FIGURA 4: Estoque de carbono até um metro nos solos no projeto RECA, em Nova Califórnia - RO.

FIGURE 4: Carbon stock up to one meter in soil profiles in the RECA project, in Nova Califórnia - RO state.

no centro do gráfico. $\mathrm{O}$ eixo $\mathrm{F} 1$ separou as áreas de Cambissolos das demais. As áreas de Latossolos e Argissolos foram agrupadas a direita do eixo F1, com exceção do perfil P4-LV, que ficou à esquerda e foi influenciado pela maior acidez, menor teor de areia e a correlação negativa com os teores de bases. $\mathrm{O}$ eixo $\mathrm{F} 2$ diferenciou as áreas principalmente pelo teor de areia. As áreas classificadas como Latossolos foram fortemente influenciadas pelos atributos: teor de bases, $\mathrm{pH}$ e teor de argila, com tendência de agrupamento no quadrante superior direito.

$\mathrm{Na}$ Tabela 6 é apresentada a matriz e correlação de Pearson para os atributos químicos e granulométricos.

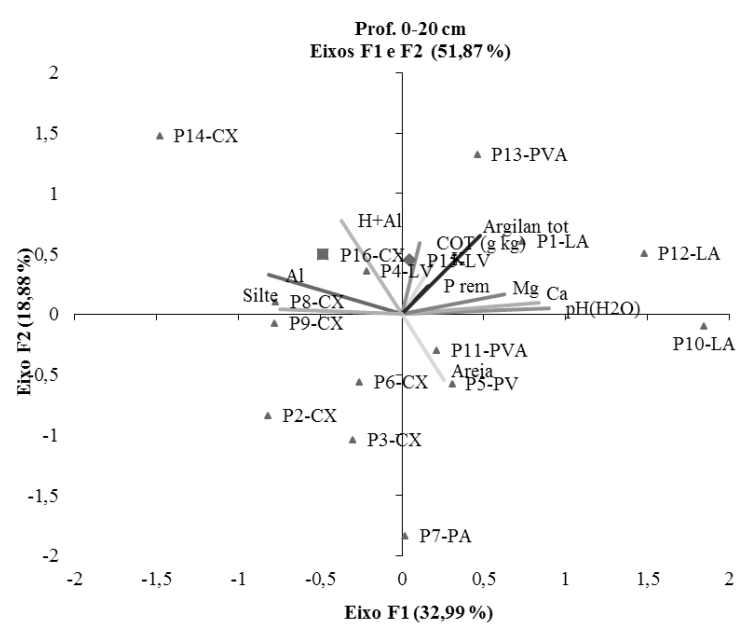

FIGURA 5: Avaliação de atributos edáficos nos SAFs $(\bullet)$ e áreas de pastagem ( ) e mata ( ) usando ACP.

FIGURE 5: Evaluation of soil attributes in the SAFs $(\bullet)$ and pasture ( ) and forest ( ) areas using PCA.

Analisando a Tabela, 6 observa-se que o atributo $\mathrm{pH}$ mostrou correlação significativa e positiva com o teor de $\mathrm{Ca}(0,914)$ e negativa com o de $\mathrm{Al}(-0,634)$, explicada pela influência do $\mathrm{pH}$ do solo na solubilidade desses elementos. Foi também observada correlação significativa entre o $\mathrm{pH}$ e os teores de argila e de silte. Para o Al foi notada ainda correlação negativa com os teores de $\mathrm{Ca}$ e $\mathrm{Mg}$, como esperado, pois esses elementos têm comportamento oposto em função do $\mathrm{pH}$. Por fim, o Al apresentou

TABELA 6: Matriz de correlação de Pearson dos atributos de solo $(0-20 \mathrm{~cm})$ em áreas de SAFs, Mata e Pastagem.

TABLE 6: Pearson correlation matrix for soil attributes $(0-20 \mathrm{~cm})$ in areas of SAF, forest and pasture.

\begin{tabular}{|c|c|c|c|c|c|c|c|c|c|c|c|}
\hline & $\mathrm{pH}$ & P REM & K & $\mathrm{Ca}$ & $\mathrm{Mg}$ & $\mathrm{Al}$ & $\mathrm{H}+\mathrm{Al}$ & COT & Argila & Areia & Silte \\
\hline $\mathrm{pH}$ & 1 & 0,095 & 0,054 & $0,914 *$ & 0,430 & $-0,634^{*}$ & $-0,357$ & 0,097 & $0,527^{*}$ & 0,078 & $-0,510^{*}$ \\
\hline P REM & & 1 & 0,267 & 0,173 & $-0,194$ & 0,136 & 0,051 & 0,191 & 0,144 & 0,250 & $-0,308$ \\
\hline K & & & 1 & 0,099 & 0,439 & $-0,144$ & 0,289 & 0,205 & 0,075 & $-0,005$ & $-0,022$ \\
\hline $\mathrm{Ca}$ & & & & 1 & 0,419 & $-0,579^{*}$ & $-0,283$ & $-0,071$ & $0,499 *$ & $-0,078$ & $-0,383$ \\
\hline $\mathrm{Mg}$ & & & & & 1 & $-0,592^{*}$ & $-0,094$ & 0,109 & 0,218 & $-0,060$ & $-0,310$ \\
\hline $\mathrm{Al}$ & & & & & & 1 & 0,364 & 0,083 & $-0,039$ & $-0,423$ & $0,602 *$ \\
\hline $\mathrm{H}+\mathrm{Al}$ & & & & & & & 1 & 0,471 & 0,216 & $-0,374$ & 0,244 \\
\hline COT & & & & & & & & 1 & 0,275 & 0,144 & $-0,250$ \\
\hline Argila & & & & & & & & & 1 & $-0,409$ & $-0,413$ \\
\hline Areia & & & & & & & & & & 1 & $-0,497$ \\
\hline Silte & & & & & & & & & & - & 1 \\
\hline
\end{tabular}

Em que: *Valores significativos a nível de significância $=0,050$ 
correlação positiva com os teores de silte, indicando que áreas com teores elevados de silte na superfície têm maiores teores de Al. Para o $\mathrm{Ca}$, a correlação foi positiva com os teores de argila.

\section{CONCLUSÕES}

Nas áreas de SAFs, os valores de RMSP em superfície não se apresentaram restritivos tendo como base os valores críticos e foram aumentando em profundidade. Em geral, os Latossolos apresentaram menores valores de RMSP quando comparados aos Cambissolos e Argissolos, devido a fatores genéticos. Os maiores valores foram encontrados na pastagem, com RMSP logo abaixo da superfície acima dos valores críticos e dos observados nas demais áreas, sendo este um reflexo do manejo da área.

O manejo das áreas com SAFs não afetou os estoques de carbono, uma vez que cerca de metade dessas áreas apresentaram estoques de carbono próximos ou superiores aos da área de mata, desta forma, os SAFs estudados tendem a ser uma alternativa para exploração econômica sem, contudo, reduzir os estoques naturais do solo nesta região.

A análise de componentes principais mostrou que as áreas de Cambissolos se distinguem das demais ordens de solo, sendo influenciadas principalmente, pelos menores teores de argila, COT, K e P rem. Nas áreas de Latossolo e Argissolo houve grande semelhança dos atributos avaliados.

\section{REFERÊNCIAS BILIOGRÁFICAS}

ACRE. Governo do Estado do Acre. Programa Estadual de Zoneamento Ecológico-Econômico do Estado do Acre. Zoneamento Ecológico-Econômico do Acre Fase II: documento Síntese - Escala 1:250.000. Rio Branco: SEMA, 2006. 354p.

AMARAL, E. F. do. et al. Uso da terra e propriedades físicas e químicas de Argissolo Amarelo Distrófico na Amazônia Ocidental. R. Bras. Ci. Solo, 28:307315, 2004.

AMARAL, E. F. do. et al. Levantamento de solos no sistema de capacidade de uso a nível de pequena propriedade rural: o caso do PED, município de Senador Guiomar, Acre. Rio Branco: Embrapa CPAFAC, 1998. 46p. (Embrapa CPAFAC. Documento, 31).

ARAÚJO, E. A. de. et al. Impacto da conversão floresta - pastagem nos estoques e na dinâmica do carbono e substâncias húmicas do solo no bioma Amazônico. Acta Amazônica, 41(1):103-114, 2011. BEUTLER, A.N.; CENTURION, J.F. Compactação do solo no desenvolvimento radicular e na produtividade de soja. Pesq. agropec. bras., 39(6):581-588, 2004.

BORGES, A.L. KIEHL, JC.; SOUZA, L.S. Alteração de propriedades físicas e atividade microbiana de um Latossolo Amarelo Álico após cultivo com fruteiras perenes e mandioca. Rev. Bras. Ci. Solo, 23:1019-25, 1999.

BRASIL. Ministério das Minas e Energia. Departamento Nacional de Produção Mineral. Projeto RADAMBRASIL. Folha SC. 19 Rio Branco. 1976. Geologia, geomorfologia, pedologia, vegetação e uso potencial da terra. Rio de Janeiro: 464 p. (Levantamento de Recursos Naturais, 12).

COLLARES, G. L. et al. Compactação de um Latossolo induzida pelo tráfego de máquinas e sua relação com o crescimento e produtividade de feijão e trigo. R. Bras. Ci. Solo, 32:933-942, 2008

D'ANDRÉA, A.F. et al. Estoque de carbono e nitrogênio e formas de nitrogênio mineral em um solo submetido a diferentes sistemas de manejo. Pesq. agropec. bras., 39(2):179-186, 2004.

EMBRAPA. Centro Nacional de Pesquisa de Solos. Sistema Brasileiro de Classificação de Solos. 2a. Edição. Brasília: Embrapa Produção da Informação; Rio de Janeiro: Embrapa Solos, 2006 306p

EMBRAPA/CNPS. Manual de métodos de análise de solos. Rio de Janeiro, 1997. 212p.

FRANKE, I. L.; LUNZ, A. M. P.; AMARAL, E. F. Metodologia para planejamento, implantação e monitoramento de sistemas agroflorestais: um processo participativo. PA/132, CPAF-Acre, 1998. $3 p$.

LIMA, H. N. et al. Mineralogia e química de três solos de uma toposseqüência da bacia sedimentar do Alto Solimões, Amazônia ocidental. Rev. Bras. Ciênc. Solo, 30(1): 59-68, 2006

NASCIMENTO, J. B. et al. Análise da compactação do solo, em áreas sob manejo sustentável no entorno de Goiânia, GO. Rev. Bras. de Agroecologia, 2(2):376-379. 2007.

RANGEL, O. J. P.; SILVA, C. A. Estoques de carbono e nitrogênio e frações orgânicas de latossolo submetido a diferentes sistemas de uso e manejo. R. Bras. Ci. Solo, 31:1609-1623, 2007

RIBON, A.A. et al. Densidade e resistência à penetração de solos cultivados com seringueira sob diferentes manejos. Acta Scientiarum: Agronomy, 25(1):13-17. 2003. 
SANTOS, R.D. dos. et al. dos. Manual de descrição e coleta de solo no campo. Viçosa, Sociedade Brasileira de Ciência de Solo, 2005. 100 p.

SOIL SURVEY STAFF. Soil Survey Manual. USDA/ SCS. Print. Office, 1993, 473p. (Handbook-18). SOUZA, Z. M. et al. Dependência espacial da resistência do solo à penetração e do teor de água do solo sob cultivo contínuo de cana-de-açúcar.
Ciência Rural, 36(1):128-134, 2006

STOLF, R. Teoria e teste experimental de formulas de transformação dos dados de penetrômetro de impacto em resistência do solo. R. Bras. Ci Solo, 15:229-235, 1991.

TAYLOR, H.M.; ROBERSON, G.M.; PARKER Jr., J.J. Soil strength-root penetration relations to medium to coarse-textured soil materials. Soil Science, 102(1):18-22, 1966. 